Int. J. Electrochem. Sci., 13 (2018) 9333 - 9345

International Journal of

ELECTROCHEMICAL

SCIENCE

www.electrochemsci.org

\title{
A Molecularly Imprinted Polythionine-Modified Electrode Based on a Graphene-Gold Nanoparticle Composite (MIP/AuNPs/rGO/GCE) for the Determination of Thrombin
}

\author{
Shaoming Yang* Jie Yang, Qiang Cao, Yue Zheng, Chaopeng Bai, Yu Teng, and Wenyuan Xu* \\ School of Materials Science and Engineering, East China Jiaotong University, Nanchang 330013, \\ Jiangxi, China \\ *E-mail: yangsm79@163.com, xwy1027@sina.com
}

doi: $10.20964 / 2018.10 .53$

Received: 16 May 2018 / Accepted: 7 August 2018 / Published: 1 September 2018

\begin{abstract}
A novel electrochemical sensor for the detection of thrombin (THR) was fabricated based on a glassy carbon electrode by the modification of molecularly imprinted polymers (MIP) and nanocomposites of graphene and gold nanoparticles. A MIP polythionine (PTH) film was formed by cyclic voltammetric electropolymerization and took the role of the redox probe to explore the sensor performance. Nanocomposites for the purpose of enhancing the sensitivity were characterized with SEM and energy dispersive spectroscopy. The stepwise preparation process of the MIP sensor was monitored with cyclic voltammetry and electrochemical impedance spectroscopy. After the experiments to determine the optimal conditions, the performance of the sensor was investigated. A linear relationship between the peak current of the PTH redox probe and the logarithm of the THR concentration was obtained over the range of $1.0 \times 10^{-8} \mathrm{~g} / \mathrm{L} \sim 1.0 \times 10^{-5} \mathrm{~g} / \mathrm{L}$ with a detection limit of $1.0 \times 10^{-9} \mathrm{~g} / \mathrm{L}$. In comparison with the non-molecularly imprinted sensor, the MIP sensor showed good anti-interference ability and high selectivity.
\end{abstract}

Keywords: Molecularly imprinted polymer $\cdot$ Polythionine $\cdot$ Nanocomposites $\cdot$ Sensor $\cdot$ Thrombin

\section{$\underline{\text { FULL TEXT }}$}

(C) 2018 The Authors. Published by ESG (www.electrochemsci.org). This article is an open access article distributed under the terms and conditions of the Creative Commons Attribution license (http://creativecommons.org/licenses/by/4.0/). 